\title{
Espaço Maker nos Anos Finais do Ensino Fundamental: Possibilidades e Desafios Vivenciados por Estudantes de Graduação do Curso de Engenharia
}

\author{
Alexandre Aragão Almeida ${ }^{1}$, Amós Costa Silva ${ }^{1}$, Camila A. M. dos Santos ${ }^{1}$, \\ Edmar Egidio P. de Souza ${ }^{1}$ \\ ${ }^{1}$ Centro Universitário Ruy Barbosa Wyden \\ Caixa Postal 41940-320 - Salvador - BA - Brasil \\ alexandrearagao.eng@gmail.com, amoscosta.tecnico@gmail.com, \\ camila.santos@frb.edu.br, edmar.souza@frb.edu.br
}

\begin{abstract}
The proposal of the Maker culture in the educational environment has attracted the interest of educators and educational institutions, as it allows the student to associate the concepts with practices, in order to make him protagonist in the construction of his knowledge. This work presents the experiences of undergraduate students in the development of activities in Maker Space in a private educational institution in the city of Salvador/BA. The adptation process of the pedagogical proposal, as well as the content design, the space organization and the pedagogical planning, is highlighted so that it can stimulate innovation and contribute to the Maker movement in education consolidating itself before the traditional educational mechanism practiced in Brazil.
\end{abstract}

Resumo. A proposta da cultura Maker no ambiente educacional tem despertado o interesse de educadores e instituições de ensino, por proporcionar ao aluno a possibilidade de associar os conceitos com práticas, de maneira a torná-lo protagonista na construção do seu conhecimento. Neste trabalho são apresentados relatos da experiência de estudantes de graduação no desenvolvimento de atividades no Espaço Maker em uma instituição privada de ensino no município de Salvador/BA, destacando o processo de adaptação da proposta pedagógica, bem como a concepção de conteúdo, a organização do espaço e o planejamento pedagógico, de maneira que possa estimular a inovação e contribuir para que o movimento Maker na educação se consolide diante do tradicional mecanismo educacional praticado no Brasil.

\section{Introdução}

Alinhar os rápidos avanços tecnológicos, com estratégias que proporcionem melhor aprendizado, necessário para cada indivíduo em sua formação enquanto sujeitos críticos, têm sido alguns dos principais desafios da educação básica . Neste aspecto, a administração escolar precisa organizar o currículo, os tempos de aprendizagens, os espaços e principalmente as metodologias para o processo formativo dos estudantes, que serão os futuros profissionais [Gavassa et al. 2016].

Ao mesmo tempo em que as tecnologias avançam, as escolas precisam transformar-se, acompanhando tendências e metodologias baseadas na aplicação de re- 
VII Congresso Brasileiro de Informática na Educação (CBIE 2018)

Anais do XXIV Workshop de Informática na Escola (WIE 2018)

cursos tecnológicos, para entre outros fatores, tornar o espaço mais atrativo para os jovens. Cada escola tem seus princípios, suas visões e seus segmentos, porém todas devem orientar e preparar o aluno para o mundo fora dela, onde a algumas competências, trabalho em equipe, capacidade de tomada de decisão e criatividade se tornam decisivas [de Alencar 2003]. O mercado de trabalho necessita de profissionais cada vez mais capacitados, com aspectos relevantes a cada segmento e com aptidões que se destaquem no meio de convívio.

O Espaço Maker tem a proposta de agregar conhecimento e valores fundamentais para tal exercício, em um ambiente totalmente intuitivo, dinâmico e estruturado [Machado and Adalberto 2016]. O aluno é condicionado à resolver problemas em forma de desafios, partindo de suposições e teorias antes vistas ou estudos sobre o determinado tema [Borges et al. 2016]. Para cada uma destas opções, a compreensão é diferenciada em relação ao método tradicional, porque a metodologia utiliza recursos tecnológicos para aprimorar os conhecimentos adquiridos em aulas expositivas (impressora 3D, cortadora a laser, kits de robótica e demais artefatos), que enriquecem ainda mais o aprendizado [Samagaia and Neto 2015].

Adequação do espaço físico, alto custo de implementação, dúvidas sobre os investimentos e planejamento pedagógico, são algumas dificuldades encontradas para levar a cultura Maker no ambiente educacional de forma sistemática e perene, no que tange a sua implantação em redes públicas de ensino. Este trabalho possui o objetivo de apresentar a experiência de estudantes de graduação de cursos de Engenharia desenvolvida por atividades como estagiários no Espaço Maker de uma escola da rede particular de ensino no município de Salvador/BA. Enfatiza-se a adequação e criação dos conteúdos, sistematização da proposta pedagógica, a organização do espaço e os resultados provenientes da participação dos alunos da escola no desenvolvimento da atividades no Espaço Maker no primeiro semestre de 2018.

\section{A cultura Maker e suas possibilidades no processo de ensino e aprendizagem}

Desde o final do século XIX a educação tradicional vem encontrando dificuldades para formar seres humanos capazes de suprir as necessidades do mundo globalizado, onde os processos de industrialização e os avanços tecnológicos, tem o crescimento exponencial. Diante dessa demanda, há a necessidade de não somente criar dominadores de tecnologia, mas brindar os alunos com a capacidade de serem inventores de suas ideias e permitir que os mesmos idealizem, planejem, criem, desenvolvam, se decepcionem, errem, tentem outras vezes e absorvam experiências para suas vidas profissionais, tornandoos empreendedores de seus próprios projetos [Borges et al. 2016].

De acordo com Blikstein (2013), independentemente da idade dos estudantes é necessário sair da zona de conforto, do lugar comum, e inovar para aprimorar tanto o crescimento cultural quanto o intelectual. Moran (2013), ainda corrobora que os espaços de aprendizagens devem ser considerados para que haja a inovação na educação. Assim como diversos projetos educacionais voltados à modernização do aprendizado em nosso país, a criação e desenvolvimento de um Espaço Maker dentro do ambiente escolar é de suma importância, principalmente no contexto de ensino tecnológico, ao qual se alinham as práticas e vivências utilizadas em ambientes de trabalho, onde tais ideias apresentam 
VII Congresso Brasileiro de Informática na Educação (CBIE 2018)

Anais do XXIV Workshop de Informática na Escola (WIE 2018)

uma série de possibilidades [Pinto et al. 2016] [Buckingham 2007].

O aprendizado baseado em desafios, surge da solução de problemas e tem como características a realidade como ponto inicial de desenvolvimento, sejam eles da comunidade ao redor, que se solucionados, afetará a vida dos indivíduos, ou na solução de problemas particulares do grupo. Devido à complexidade, cada projeto é desenvolvido em sistema de cooperação, exigindo um trabalho em equipe de forma interdisciplinar .

Tal sistema expositivo de aprendizado oportuniza também o manuseio de ferramentas manuais, onde a desenvoltura individual e o compartilhamento de informações é de suma importância para um bom desenvolvimento, podendo sim se juntar ao manuseio de elementos robóticos, para uma total funcionalidade [Júdice et al. 2016]. Dar ao aluno a possibilidade de usar sua criatividade em projetos no meio acadêmico é uma forma de mesclar a teoria com a prática [Cardoso et al. 2013]. Essa é a proposta que se dá na implementação da Cultura Maker.

\section{Métodologia Desenvolvida}

A metodologia e às atividades descritas neste trabalho foram desenvolvidas e aplicadas por alunos de graduação de cursos de Engenharia, como parte do estágio curricular do curso. As atividades no colégio iniciaram-se em Janeiro de 2018, período pré aulas, para adequação nas instalações, fiscalização de todo o processo de estruturação do espaço físico e estudo dos objetivos principais do projeto, que foi todo implantado por uma empresa (ementa, planejamento e orientações).

De posse dos informes, realizou-se análise das atividades à serem desenvolvidas com os alunos e apesar destas estarem prontas, uma análise anterior por parte da direção de ensino local, definiu como insuficientes para uma realidade atual de aprendizados com tecnologias, requerendo adequações em todos os quesitos. A partir destas ordens, uma nova proposta foi montada, trazendo a vivência universitária como base para criações de novas atividades. Visando dissolver o conceito comumente utilizado de dificuldade "fácil/difícil", cada projeto foi subdividido em dois níveis de construção, identificados com o nome de um criador ou autor alinhado à proposta e ao tema de cada série, para que se tenham variadas situações de construção e induza a pesquisa sobre tal inventor. $\mathrm{O}$ primeiro nível contém mais trabalhos manuais e que demandam a criatividade do aluno. Já o segundo nível trabalha mais a desenvoltura do aluno, induzindo-o ao pensamento crítico e a análise de construção, possibilitando também o uso de ferramentas mais complexas como a impressora 3D, manuseio de instrumentos eletrônicos, além da cortadora a laser. Em cada ano, definimos dois inventores a algo relacionado ao objetivo da atividade:

- $6^{\circ}$ ano: Robert Lang (Mestre em artes com origami e desenvolvedor de novas técnicas para dobraduras em papel) e Galileu (Físico importante na revolução científica).

- $7^{\mathbf{0}}$ ano: Henry Ford (Fundador do primeiro sistema de montagem em série).

- $8^{\circ}$ e $9^{\circ}$ ano: Volta (Físico criador da primeira bateria elétrica) e Thomas (Cientista e inventor da lâmpada incandescente).

Cada nível foi trabalhado de forma sequencial, cabendo ao grupo criar mecanismos de desenvoltura para finalização do projeto. Devido à restrição de espaço do laboratório, os estudantes foram separados em grupos dentro de cada turma devendo ter encontros quinzenais, uma vez que esta turma é dividida com a matéria de artes pela grande 
VII Congresso Brasileiro de Informática na Educação (CBIE 2018)

Anais do XXIV Workshop de Informática na Escola (WIE 2018)

quantidade de alunos com aulas de 75 minutos cada. Nas primeiras semanas uma breve apresentação do espaço foi necessário, para retirada das primeiras impressões dos alunos quanto à desenvoltura com o novo ambiente, deixando bem claro as regras e objetivos de tais atividades. Uma dinâmica foi feita em cada turma, utilizando-se ferramentas manuais e instruções de seu uso correto: um corte em madeira utilizando o arco de serra manual e a fixação de pregos em duas placas de madeira. Para cada atividade, a explicação do uso dos Equipamentos de Proteção individual (EPI's) foi de fundamental importância, pois muitos nem conheciam tal termo ou instrumento.

\section{Resultados e Discussões - Relatos de Experiência}

\subsection{Atividades desenvolvidas com alunos do $6^{\circ}$ ano.}

O objetivo para o sexto ano é fundamentar os alunos com noções básicas de princípios e relações mecânicas dando um horizonte, a princípio, inexplorado. Normas serão dadas e testadas para comprovarem sua eficácia. O ideal é levantar dúvidas e o próprio alunado testificar o êxito, ou não, das experiências. Permitir que se haja erros será uma forma de proporcionar ao aluno criar soluções criativas para que seu problema seja resolvido. Todo esse aprendizado será dado juntamente com o uso de ferramentas mecânicas e elétricas, tornando o uso dessas cada vez mais familiar aos alunos.

\subsubsection{Nível Robert Lang}

Dama em papelão: Cortando pedaços de cabo de vassoura com o arco de serra, que serviu como peças para o jogo e um tabuleiro moldado e enfeitado em pedaços de papelão, esta foi a atividade inicial. Ao total foram utilizadas três semanas para conclusão desta e diversas ferramentas diferentes foram usadas como desafios de aprendizagem, como por exemplo o estilete, régua e paquímetro. No decorrer desta atividade, observou-se que alguns estudantes tiveram maior dificuldade com utilização de ferramentas simples, como por exemplo uma régua e outros com um certo receio ou medo de pegar em materiais mais complexos, o que demonstra a total necessidade de atividades como essa. Este fato ocorreu em diversas outras experiências com ferramentas, influenciando nas atividades posteriores e necessitando de uma atenção especial.

Pipa : Utilizando palitos de churrasco feitos em madeira ou talos de bambu e colado com cola branca em um papel de seda, a rabiola foi feita com papel crepom colorido, deixando o aluno livre para enfeitá-la, induzindo a criatividade individual. Esta foi a segunda atividade feita nas turmas, porém ao contrário das outras atividades trabalhadas em grupo, esta foi uma atividade individual, devendo cada um criar da maneira que bem entender. Além da construção desta, os mesmos foram para uma aula de campo, testar e se divertir com os objetos criados em um parque ambiental da cidade do Salvador, o Parque de Pituaçu, justamente para mostrar a capacidade e a funcionalidade dos brinquedos montados em sala. Esta atividade apresentou relevância, pois se observou que os alunos realmente se impressionaram com os objetos criados e não acreditavam que poderia funcionar, o que influenciou totalmente nas atividades seguintes, o empenho de todos foi bem maior, uma vez que a atividade tinha sido um sucesso. Outro ponto relevante, foi o total desafio de montar objetos individuais e dar atenção a todos os alunos ao mesmo tempo, 
VII Congresso Brasileiro de Informática na Educação (CBIE 2018)

Anais do XXIV Workshop de Informática na Escola (WIE 2018)

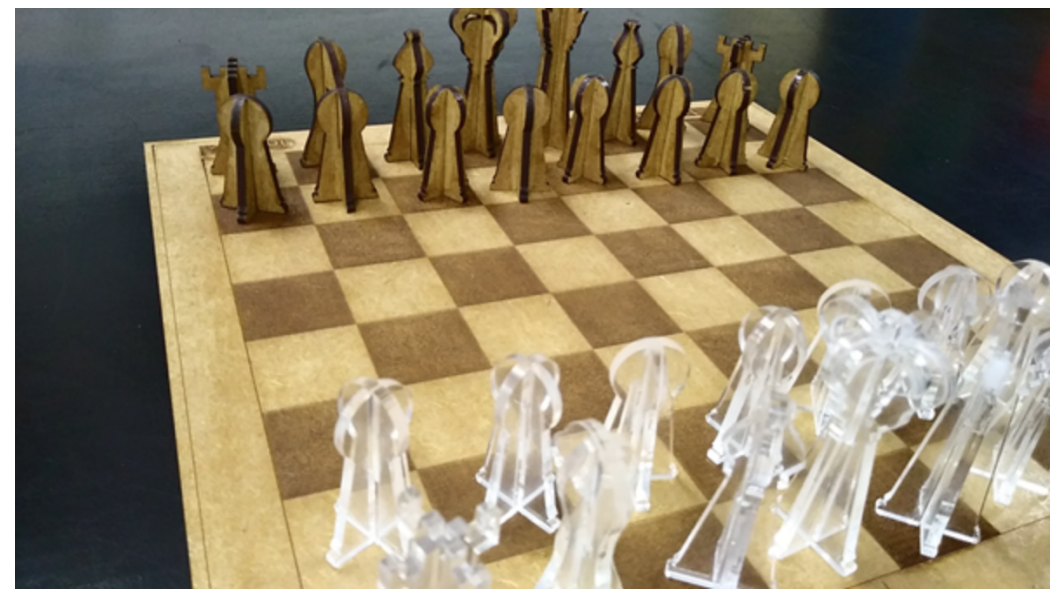

Figura 1. Xadrez plano de madeira

para esta atividade foi de extrema importância a presença de dois orientadores na sala, facilitando assim no desenvolvimento com todos e reduzindo o tempo de confecção.

\subsubsection{Nível Galileu}

Carro de papelão: Através de um desenho/molde o aluno desenvolveu o recorte do papelão usando dobras e encaixes. Esta atividade foi fundamental para conhecimento dos materiais utilizados nas confecções e o aprendizado sobre técnicas que podem ser utilizadas em diversos artigos como o papel, fitas e etc. Um molde cortado previamente na cortadora a laser poderia ser utilizado, mas muitos preferiram pesquisar outros modelos possíveis de construção aos quais os agradavam.

Xadrez plano de madeira: Esta atividade foi projetada para utilização da cortadora a laser, porém para aulas expositivas e momentos de distração, com o intuito de demonstrar na prática as regras do jogo e adquirir habilidades estratégicas.

\subsection{Atividades desenvolvidas com os alunos do $7^{\circ}$ ano}

O objetivo para o sétimo ano é mostrar ao aluno uma visão estratégica e planejada da construção de um projeto, dando ao mesmo ferramentas de organização de ideias. O aluno deve ter como foco iniciar e terminar o projeto, usando passos chaves que o dará uma pré-visualização do seu produto. Foi mostrado também conceitos de manipulação/elevação de forças e seu funcionamento em diversas áreas do cotidiano.

\subsubsection{Nível H.Ford}

Guindaste (Polia-manual) - Consiste em elevar objetos de diferentes pesos utilizando a menor força possível com um sistema de polias manuais, deixando livre o design. Esta atividade durou 4 semanas, sendo a mais duradoura dentre as demais por conta da sua complexidade. Mesmo com todas as explicações dos materiais que estavam em suas mãos, perigos e cuidados a se tomar, eles brincavam demais nas confecções das atividades, pondo em risco a si próprio e aos demais que estavam presentes, principalmente 
VII Congresso Brasileiro de Informática na Educação (CBIE 2018)

Anais do XXIV Workshop de Informática na Escola (WIE 2018)

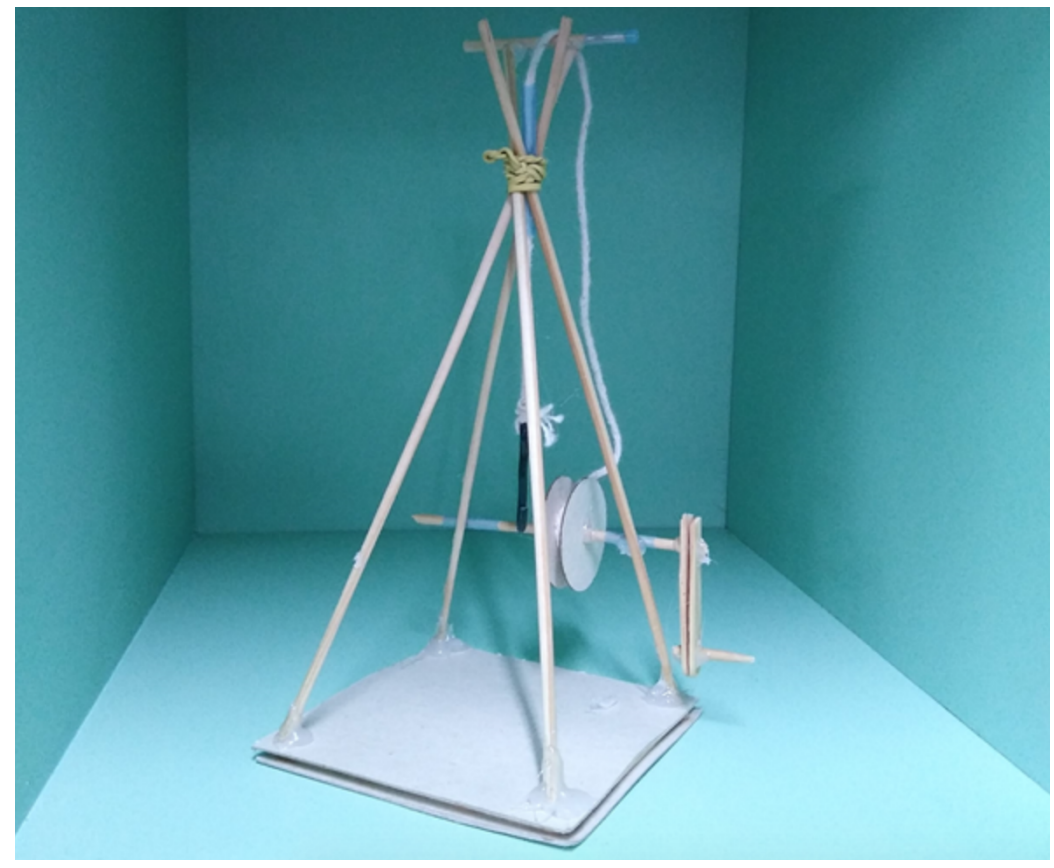

Figura 2. Confecção do guindaste

grupos de dispersos, aos quais se obteve uma maior quantidade de acidentes leves proveniente deste tipo de brincadeira. O material com maior queixa é a pistola de cola quente que, aparenta ser inofensiva, mas causa graves queimaduras na pele, o que aconteceu algumas vezes dentre as aulas.

Dínamo - Por meio de um princípio de mudança de pólos que se utilizará de um motor DC, este sistema tem como finalidade mostrar a geração de eletricidade através de forças motrizes e fazer a analogia a sistemas hidrelétricos é uma forma de exemplificar e explicar como funcionam e esta analogia foi extremamente importante para um maior interesse deles, pois realmente eles tinham um exemplo prático e aplicação de tal atividade. Antes desta atividade, fizemos uma aula de experimentações e explicações. Percebendo a dificuldade de muitos com a utilização de ferramentas, decidimos utilizar uma aula somente para a explicação do manuseio correto de todos os equipamentos necessários para a confecção do projeto.

Esta aula apresentou resultados interessantes, pois todos os alunos ficaram familiarizados com os materiais e puderam perceber a dificuldade ou facilidade na utilização de cada equipamento, riscos e melhor posicionamento, facilitando no seu desenvolvimento e diminuindo riscos de acidentes. Durante o desenvolvimento, muitos questionaram a importância de tal objetivo: a geração de energia, trouxeram fatos curiosos que aconteceram com eles em algum momento, o que engrandeceu mais as aulas, além de que alguns alunos associaram com projetos externos que eles participam, como por exemplo o de robótica avançada e entre outros.

\subsection{Atividades desenvolvidas com os alunos do $8^{\circ}$ ano e $9^{\circ}$ ano}

As atividades desenvolvidas têm grande foco em conceitos elétricos passando por componentes eletrônicos, como por exemplo leds, resistores e conectores. Baseado neste aprendizado, o aluno deverá desenvolver visão crítica sobre sistemas eletromecânicos po- 
VII Congresso Brasileiro de Informática na Educação (CBIE 2018)

Anais do XXIV Workshop de Informática na Escola (WIE 2018)

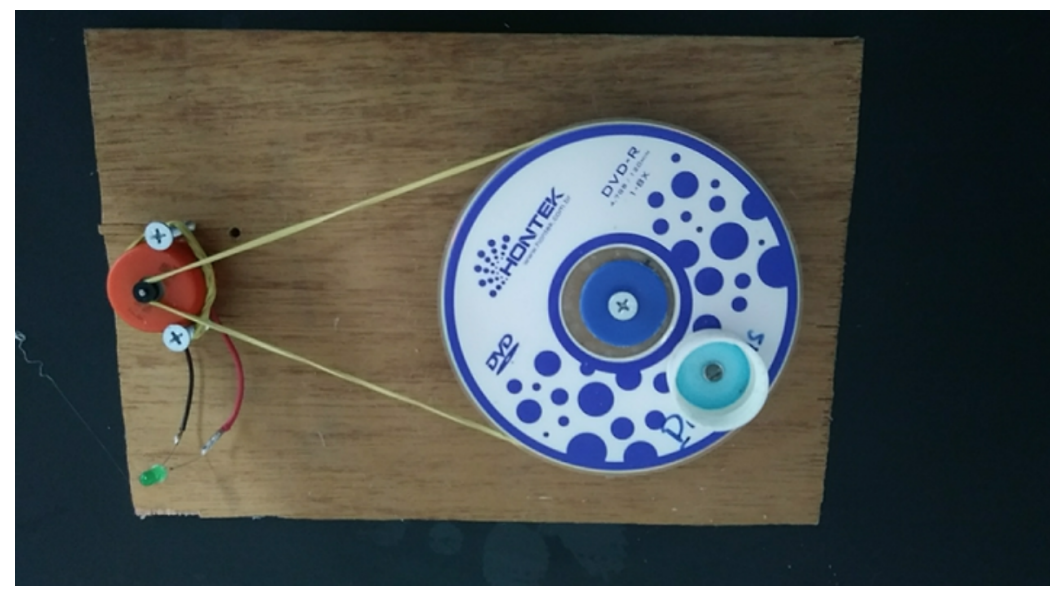

Figura 3. Desenvolvimento do experimento Dínamo

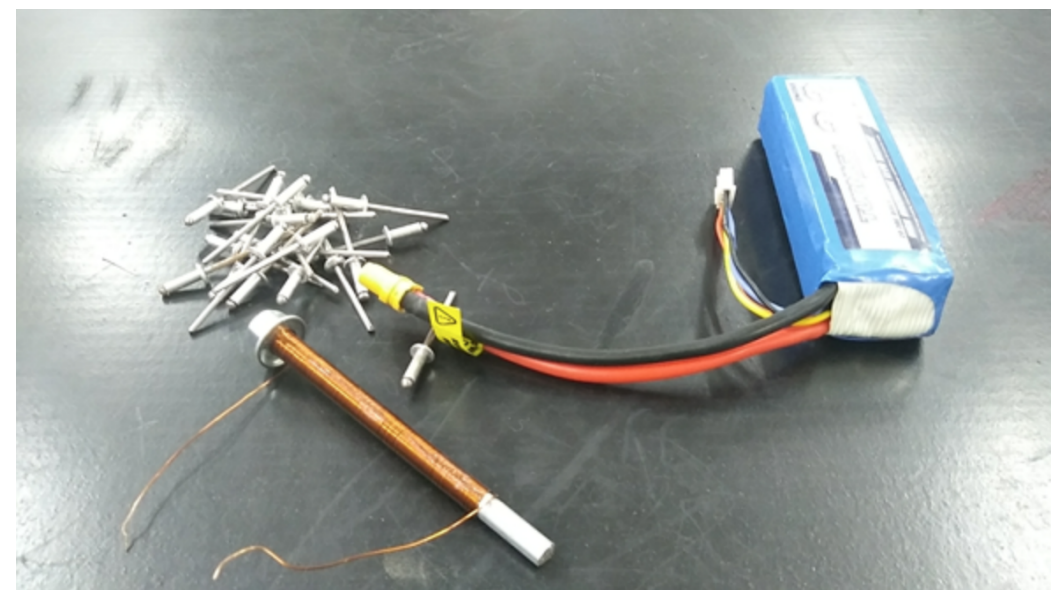

Figura 4. Protótipo do eletroímã

dendo assim desenvolver protótipos, formando em si o espírito empreendedor. Com a utilização de sistemas embarcados, como o microcontrolador arduino, irão desenvolver pilotos. Ferramentas como estação de solda, multímetros, estanho e utensílios de proteção como fitas isolante e termoretráteis serão aprendidos no uso.

\subsubsection{Nível Volta}

Eletroímã - Através de alguns metros de cobre e um pedaço de metal, foi desenvolvido um protótipo capaz de atrair metais ou simplesmente gerar calor. $\mathrm{O}$ dispositivo tem como a finalidade inicial, gerar um campo magnético pela corrente elétrica que passará no enrolamento de cobre. O importante é que o aluno note o comportamento do protótipo com duas diferenças de grandezas. Uma vez que tenha uma alta tensão o eletroímã irá ter mais força de atração. Numa outra situação onde tenhamos uma corrente maior o protótipo irá gerar calor ao invés de atrair. Com essas relações foi aberto um leque de oportunidade que dependerá de o aluno aplicar em algo próprio.

Após desenvolver o protótipo, os alunos puderam notar a diferença entre duas grandezas físicas importantes no nosso mundo. Por parte de alguns foi notável o aprendi- 
VII Congresso Brasileiro de Informática na Educação (CBIE 2018)

Anais do XXIV Workshop de Informática na Escola (WIE 2018)

zado sobre o assunto. Em algumas turmas foi possível fazer algumas experiências como aquecer água, derreter gelo ou qualquer outro material. A experiência foi proveitosa pois com isso, também, pudemos mostrar a atuação do campo eletromagnético.

Sistema em Série/Paralelo: Circuito básico de energia com leds, resistores, interruptores, entre outros componentes. Tem como principal razão em montar um quadro simples de energia, mostrando o funcionamento de um circuito fechado. O mesmo mostra o uso da energia em cada sistema e seu comportamento. Além disso o aluno irá ter a noção básica de eletrônica, conhecendo a protoboard. Com esta atividade foi possível ver nos alunos o interesse de uns que fizeram além do pedido, colocando em prática o que foi aprendido. Desta atividade surgiu o interesse para fazer outras como: robôs autônomos, drones, sistemas de proteção, mãos robóticas e outras. O ponto de maior dificuldade nessa atividade foi mostrar ao aluno as suas possibilidades de desenvolvimento. Muitas vezes eles já têm algo em mente para fazer, mas a não interpretação dificulta os próximos passos.

\subsubsection{Nível Thomas}

Buzzer (usando um acionador reciclado) - Desenvolver um sistema de alarme que tenha juntamente com o sistema de iluminação, a função de gerar atenção. A ideia é estimular o espírito empreendedor nas suas necessidades. Está atividade foi a continuação da atividade anterior, mas nessa segunda parte foi colocado um cunho de desafio. A proposta em si é notar a possibilidade de criar com coisas simples, sem muitas alternativas. Os alunos tiveram dificuldade até sair da zona de conforto e notar que a vontade de criar mudou as expectativas deles. O êxito desta atividade depende muito da forma que a turma se comporta. Com algumas turmas foi possível desenvolver essa atividade juntamente com opções paralelas dadas pelos próprios alunos. Por fim, essa atividade nos serviu para fazer um fechamento mais completo da atividade anterior.

Automação Residencial - Construir um sistema elétrico residencial com lâmpadas. A alimentação contou com uma tensão proveniente do laboratório e seguiu os padrões de segurança para tal instalação. O uso do microcontrolador Arduino foi adotado para fazer a parte lógica. Com essa atividade foi possível mostrar o funcionamento de forma mais notável da instalação de uma residência, revisando ligações em paralelo/série e tendo de fato uma experiência do comportamento dos dispositivos sob essas ligações. $\mathrm{O}$ principal intuito foi exibir a simplicidade de um sistema automático residencial. Foi importante criar algumas aulas teóricas para mostrar os cuidados com a energia, mostrando os sistemas de segurança, as formas de se criar caminhos (emendas) e a forma correta de fazer o isolamento para evitar fugas de correntes e acidentes indesejados. Nesta atividade foi possível mostrar mais a fundo o uso de microcontroladores no ambiente educacional. Após esta atividade tivemos uma visita mais frequente de alunos que gostariam de desenvolver suas ideias com sistemas controladores. Em resumo, tivemos um feedback positivo com relação ao desenvolvimento prático dos alunos, que por sua vez já começam a elaborar atividades mais ligadas a física e eletrônica, sendo cada vez mais complexas as ideias e para nós gratificante. 
VII Congresso Brasileiro de Informática na Educação (CBIE 2018)

Anais do XXIV Workshop de Informática na Escola (WIE 2018)

\section{Conclusões e Considerações Finais}

Com o rápido avanço tecnológico e suas variadas inovações sofridas pela sociedade, os jovens estão cada vez mais autônomos e curiosos. No decorrer do processo de criação dos projetos, os estudantes obtiveram experiências antes nunca tidas em um ambiente escolar, em um espaço totalmente novo e moderno, onde as suas ideias são as principais fontes de receitas. A cada final de projeto, uma conversa com os alunos torna-se fundamental, trazendo pontos positivos e negativos, conteúdos teóricos que não enxergaram gerando discussões ao longo da proposta desenvolvida, a fim de despertar a associação no próprio com os assuntos contidos em matérias elementares. Isso foi bastante relevante, pois os alunos perceberam que suas opiniões trariam melhorias para os próprios, estimulando cada vez mais as suas competências. Tradicionalmente as pessoas escolhidas para formar os grupos, vinham do nível de aproximação nas turmas, o que acabou facilitando o entrosamento de cada um, porém uma breve análise constatou que nos grupos formados somente por meninas, apesar de serem mais sujeitas a rejeições para algumas atividades, eram os grupos com melhores ideias e organizações, mostrando ainda mais a total contrariedade das demais experiências anteriores.

Outro ponto de relevância foi que como muitas atividades já indicavam o objetivo final dos objetos, o que mais eles pediam, era para que tivéssemos aulas no estilo "Open Day", onde o aluno poderia ser livre para a confecção de um projeto de seu interesse, o que agregaria ainda mais o aprendizado. Os objetivos do movimento Maker ainda estão em expansão, porém já se mostram condizentes com os resultados obtidos pelas atividades desenvolvidas com os alunos do ensino fundamental II. Apesar de alguns demonstrarem falhas durante todo o processo de construção, o resultado final dos projetos os deixavam orgulhosos e surpresos com suas próprias habilidades, motivando-os ainda mais para novos desafios. O contexto "mão na massa"engrandeceu as relações pessoais e cooperação entre os indivíduos, pois cada um ajudava o outro nos materiais que tinham maiores conhecimentos de manuseio, auxiliando também no processo de criação. A presença de ferramentas tecnológicas e um ambiente repleto de opções manuais estimulou os desenvolvedores a não se limitarem somente no básico, procurando novas formas de solução para tais problemas, fato que despertou a criatividade individual dos grupos, características únicas que estão presentes em ambientes de desenvolvimento.

Diante destas atividades relatadas neste artigo, espera-se que possam servir de inspirações para uma mudança no pensamento geral de aprendizado em escolas públicas ou privadas, dando maior oportunidade de crescimento individual a cada um. Com estes projetos, os alunos aumentaram o nível de satisfação e interesse com tais instituições, uma vez que utilizaram de seus aprendizados teóricos para a construção de algo concreto, bem como se tornam mais criativos se sentindo estimulados e capacitado para projeções futuras.

\section{Referências}

Borges, K. S., de Menezes, C. S., and da Cruz Fagundes, L. (2016). Projeto maker como forma de estimular o raciocínio formal através do pensamento computacional. $V$ Congresso Brasileiro de Informática na Educação (CBIE 2016), pages 1-10.

Buckingham, D. (2007). Crescer na era das mídias eletrônicas, volume 1. Loyola. 
VII Congresso Brasileiro de Informática na Educação (CBIE 2018)

Anais do XXIV Workshop de Informática na Escola (WIE 2018)

Cardoso, A. M., de Freitas Azevedo, J., and Martins, R. X. (2013). Histórico e tendências de aplicação de tecnologias no sistema educacional brasileiro. Revista Digital da CVA, pages $1-11$.

de Alencar, E. M. L. S. (2003). Contribuições teóricas ao estudo da criatividade. Revista Psicologia: Teoria e Pesquisa, pages 1-8.

Gavassa, R. C. F. B., Munhoz, G. B., de Mello, L. F., and Carolei, P. (2016). Cultura maker, aprendizagem investigativa por desafios e resolução de problemas na sme-sp (brasil). FabLearn Org, pages 1-9.

Júdice, A. C. B., Maynardes, A. C., Júdice, M. O., and Aviani, F. L. (2016). Fabricação digital e identidade de territórios em produtos cotidianos. SIGraDi 2016, pages 1-6.

Machado, E. and Adalberto, L. (2016). Movimento makers e a aprendizagem criativa no ensino da matemática no fundamental 1. Educação Matemática na Contemporaneidade: desafios e possibilidades, pages 1-8.

Pinto, S. L. U., de Azevedo, I. S. C., Santos, G. S. P., Hamad, A. F., and Teixeira, C. S. (2016). O movimento maker: Enfoque nos fablabs. 26th Conferência ANPROTEC, pages $1-16$.

Samagaia, R. and Neto, D. D. (2015). Educação científica informal no movimento maker. EX Encontro Nacional de Pesquisa em Educação em Ciências ENPENC, pages 1-8. 